\title{
Constrained vs Unconstrained Labor Supply: The Economics of Dual Job Holding *
}

\author{
Chung Choe ${ }^{\dagger}$ \\ Hanyang University, Korea \\ Ronald L. Oaxaca \\ University of Arizona, USA \\ LISER, Luxembourg, IZA, Germany, PRESAGE, France \\ Francesco Renna ${ }^{\S}$ \\ University of Akron, USA
}

August 6, 2017

\begin{abstract}
This paper develops a unified model of dual and unitary job holding based on a StoneGeary utility function. The model incorporates both constrained and unconstrained labor supply. Panel data methods are adapted to accommodate unobserved heterogeneity and multinomial selection into 6 mutually exclusive labor supply regimes. We estimate the wage and income elasticities arising from selection and unobserved heterogeneity as well as from the Stone-Geary Slutsky equations. The labor supply model is estimated with data from the British Household Panel Survey 1991- 2008. Among dual job holders, our study finds that the Stone-Geary income and wage elasticities are much larger for labor supply to the second job compared with the main job. When the effects of selection and unobserved heterogeneity are taken account of, the magnitudes of these elasticities on the second job tend to be significantly reduced.
\end{abstract}

Keywords: dual job; labor supply; Stone-Geary; hours constraint

JEL classification codes: J01; J22; J49

\footnotetext{
${ }^{*}$ We thank three anonymous referees for comments that greatly improved the paper. We also gratefully acknowledge the helpful comments of Changhui Kang, Tiemen Woutersen and participants at the 14th IZA/SOLE Transatlantic Meeting of Labor Economists, as well as seminar participants at CEPS/INSTEAD, University of Bari, University of Lecce, and University of Rome. This work was supported by the Ministry of Education of the Republic of Korea and the National Research Foundation of Korea (NRF-2015S1A5A8014290).

${ }^{\dagger}$ Chung Choe, Hanyang University ERICA Campus, 55 Hanyangdaehak-ro, Sangnok-gu, Ansan, Gyeonggi-do, 426-791, Korea . Phone: +82-31-400-5651. Fax: +82-31-400-5593. E-mail: choechung@ hanyang.ac.kr.

${ }^{\ddagger}$ Ronald Oaxaca, Department of Economics, McClelland Hall \#401, Eller College of Management,University of Arizona, P.O. Box 210108, Tucson, AZ 85721-0108. Phone: +1 5206214135. Fax: +1 5206218450. E-mail: rlo@email.arizona.edu.

${ }^{\S}$ Francesco Renna (corresponding author), Department of Economics, CAS \#447, University of Akron, Akron, OH 44325-1908. Phone: +1 3309727411. Fax: +1 3309725356. E-mail: frenna@uakron.edu.
} 


\section{Introduction}

Researchers have progressively extended labor supply theory in both static and dynamic dimensions to account for a richer variety of labor supply behavior. One fruitful area for research on labor supply is that of multiple job holding. One of the most interesting aspects of multiple job holding is the motivation behind the decision to hold more than one job. A number of studies show that this decision is not only motivated by an hours constraint on the main job (also known as moonlighting), but also by a desire to hold a portfolio of jobs. Mostly, this literature has focused either on the determinants of each decision or on the labor supply for only one of the possible regimes. Considerably less attention has been paid to the development of a general labor supply model that allows for moonlighting as a response to an hours constraint on the main job and the joint determination of the hours supplied to two jobs when the decision to hold two jobs is not dictated by a constraint on the main job. In this paper we develop such a labor supply model based on a Stone-Geary utility function which allows us to model the choices of an individual who can hold up to two jobs.

Dual job holding is a pervasive phenomenon in many economies. Between 1994 and 2002, the weekly rate of dual job holding in the U.K. was around 4.5 percent (Office for National Statistics, 2002), but when computed on a monthly basis, the rate was found to be almost twice as high (Panos et al., 2011). If at any point in time the number of people holding two jobs may appear small, the reality of dual job holding seems to touch a large number of individuals over their working life. In our sample of British working age males, we estimated that 15 percent held two jobs at least once between 1991 to 2008 . This result is in line with the findings for the US, where Paxson and Sicherman (1998) found that while only 5-6 percent of the US population holds two jobs in any particular week, about 20 percent of working males held a second job between 1976 to 1989 . Moreover, on average 17 percent of all hours worked in a given year consists of hours worked on a second job. Dual job holding seems quite common in developing and transition economies as well, where the incidence of domestic production that takes place in the informal sector is typically higher than in developed countries. The rate of dual-job holding Russian males doubled from the early to the mid 90's and stayed around 12 percent for the remainder of the decade (Foley, 1997). A survey of Tanzanian workers with a regular job in the formal economy found that more than half of them also held a job in the informal sector (Theisen, 2009). 
Dual job holding is typically associated with an hours constraint on the main job. Firms generally offer a fixed hours and wage employment package subject to labor market regulations or union contracts pertaining to overtime. If the number of hours that a firm offers falls short of the optimal number of hours that a utility maximizing worker would choose at the going wage, then a rational individual will take a second job under the condition that it pays more than his reservation wage on the second job. This is what we regard as the hours constraint motivation for holding multiple jobs, or "moonlighting". Moonlighting can be viewed as a substitute (perhaps temporary) for search for a job with the optimal package of hours and wage rate. However, moonlighting alone cannot explain the behavior of all dual job holders. In fact, Allen (1998) concludes that unconstrained workers are more likely to have two jobs than are constrained workers. This result has led to a rich line of research on the motivation behind the decision to hold two jobs. Some individuals may decide to allocate their working time between two or more jobs because they have a personal preference for job differentiation. For example, some workers may hold two jobs because jobs are heterogeneous and they are not perfect substitutes (Kimmel and Conway, 2001). Others may hold a second job as a form of hedging against the risk of losing employment (Bell et al., 1997) or as a form of hedging against a wage risk (Lundborg, 1995). Also dual job holding can be a way to gradually transition to a new primary job, often self-employment (Panos et al., 2011) or as a substitute for a spouse entering the labor market (Krishnan (1990)). While individuals may be able work their desired hours on their main job, they may allocate some of their hours to a second job because the second job offers a more convenient schedule. We group under the job portfolio label all reasons for holding two jobs that are not due to an hours constraint.

In this paper we expand on Kimmel and Conway (2001) by using a Stone-Geary utility function to motivate the empirical work in the context of a dual job holding model. ${ }^{1}$ Here the Stone-Geary utility function is used to model the choice of a worker that can hold up to two jobs. The estimation is carried out for a sample of male workers from the British Household Panel Survey (BHPS).

The sample is restricted to men to avoid standard selection problems associated with the labor supply decision of women. ${ }^{2}$ We also exclude self-employed individuals on the main job as the hours constraint argument does not typically apply to their situation. For dual job holders

\footnotetext{
${ }^{1}$ Typically the Stone-Geary utility function is used to estimate expenditure functions for multiple commodity groups. See Chung (1994) for a review of the main studies based on a Stone-Geary utility function.

${ }^{2}$ In fact, the male participation rate in our sample is 90 percent while the same rate for women is only 74 percent.
} 
we restrict our sample to those with a paid second job which can include some who are selfemployed on the second job. We use recent developments in econometrics to model unobserved heterogeneity and sample selection in a panel data setting. We derive the labor supply functions for unitary and dual job holders. For the latter, we distinguish whether or not they face an hours constraint on the main job. If there is an hours constraint on the main job, does it produce overemployment or under-employment? In addition we extend binary sample selection methods for panel data to multinomial selection into one of 6 mutually exclusive labor supply outcomes in the presence of unobserved heterogeneity. From our estimates, we compute the wage elasticities and income elasticities for each category of worker according to their constrained and dual-job status. Furthermore, the derived Slutsky elasticities are supplemented by wage and income effects associated with selection and unobserved heterogeneity. We confirm the results in the literature that the labor supply for a unitary job holder is quite inelastic (Altonji and Paxson, 1988). While the own wage elasticities are always in absolute value less than 1 , a $1 \%$ increase in the wage for job 1 would decrease the hours supplied to job 2 by 5 to $7 \%$ depending on labor supply regime. Importantly our results reveal how failure to control for selection and unobserved heterogeneity can lead to seriously biased estimations of the own wage elasticities.

Section 2 reviews the literature on dual job holding; section 3 is an overview of dual job holding in the UK; section 4 presents the theoretical framework used to derive our labor supply equations; section 5 describes the data; section 6 discusses the estimation strategies of our empirical models; section 7 presents the empirical findings; and section 8 is a summary and conclusion.

\section{Literature Review}

Early theoretical work focused only on the hours constraint aspect of moonlighting (Perlman, 1966). Shishko and Rostker (1976) and Frederiksen et al. (2008) found that labor supply becomes more elastic to changes in the wage rate after accounting for the decision to moonlight. Paxson and Sicherman (1998) concluded that moonlighting is a short-run solution to a situation of under-employment, while searching for a job that offers the target hours of work. However, the latter result is not supported by other studies that found that dual job holding is quite persistent over time and not just a short-run decision, thus casting doubt on the hours constraint hypothesis (Böheim and Taylor, 2004; Panos et al., 2011). 
A number of papers have tried to identify the determinants and hence the motives behind the decision to hold two jobs. Typically all studies conclude that while the probability of holding two jobs increases in the presence of hours or liquidity constraints (Abdukadir, 1992; Kimmel and Conway, 2001; Panos et al., 2011), unconstrained workers are actually more likely to hold two jobs than constrained workers, thus suggesting that job portfolio motives may be even more important than the hours constraint (Allen, 1998; Böheim and Taylor, 2004). Exploiting the information contained in the 1991 Current Population Survey, Averett (2001) can identify the motives for holding two jobs. She classified as moonlighters all individuals who report working on a second job (1) to meet regular household expenses, (2) to pay off debts, (3) to save for the future or (4) to buy something special. She identified as dual job holders with job portfolio motives all individuals who report working on a second job (1) to get experience in a different occupation or to build a business, (2) to help out a friend or relative, (3) because he/she enjoys the work on the second job, and (4) other reasons. She estimated the probability of being a moonlighter, conditional on being a dual job holder, but she is unable to identify any specific determinant that is consistently significant across alternative models.

Only a handful of papers have actually attempted to estimate labor supply models that include the hours constraint and the job portfolio motive as alternative motives to working on a second job. Wu et al. (2009) estimated a labor supply function on the second job that included an indicator for being satisfied with the hours worked on the main job, but failed to recognize that the specification of labor supply for moonlighters is different from that associated with the job portfolio hypothesis. In particular, the hours supplied on the first job should be included in the labor supply equation for the second job for moonlighters but not in the labor supply equation for the second job in the job portfolio model. To the best of our knowledge, Kimmel and Conway (2001) is the only attempt that recognizes this important distinction. However, their data does not allow them to identify whether the decision to work on a second is motivated by an hours constraint. Consequently, they first need to estimate the probability that a moonlighter faces an hours constraint on the main occupation using a disequilibrium model. They then use these predicted probabilities to estimate the alternative labor supply using a switching regression model. Although they work with panel data, no attempt is made to control for individual unobserved heterogeneity. 


\section{Dual Job Holding in the UK}

While the primary empirical analysis is based on only male workers in paid employment, we present some basic characteristics of the sample of dual job holders in the BHPS. In Figures 1 and 2 we report the dual job holding rates for men and women between 1991 and 2008 separately by type of employment on the main job. Only 17 percent of all individuals in the survey are self-employed on the main job (less than a third is comprised of women). For workers in paid employment the monthly rate hovered around 10 percent until 2000 with rates slightly higher for women. After 2000, the rates dropped to about 7 percent. This drop may have been driven by a change in the composition of the sample in the survey following the addition of an oversample of households from Scotland and Wales and the introduction of a sample of households from Northern Ireland. For self-employed the dual job holding rate is more stable over time. Again the rate for women is higher than for men.

Table 1 looks specifically at male dual job holder workers in paid employment on the main job. The occupational distribution on the main job for dual job holders is similar to the distribution for unitary job holders except for the fact that dual job holders seem less represented among "Managers and Administrators" and slightly more represented among "Personal and Protective Services". The occupational distribution on the second job seems to differ dramatically from the distribution on the main job. A considerably lower percentage of workers hold a managerial, clerical, or operative position on their second job compared to the first job, while a much higher percentage of workers hold a technical or service related job for the second job. Given how different the distributions of occupations on the main and second job are, it is not surprising that only 30 percent of our sample holds a second job in the same occupation as the main job. Occupation matching is more likely among workers with specialized skills such as technical and craft worker. ${ }^{3}$ Occupation matching is least likely among managers, sales, and operatives.

\section{Conceptual Framework}

In this section we introduce the theoretical labor supply functions obtained from utility maximization for a Stone-Geary Utility function. Our approach is motivated by a desire to understand dual-job labor supply from the perspective of a carefully articulated utility maximization

\footnotetext{
${ }^{3}$ This result is consistent with Panos et al. (2011) which finds that workers who have a lower degree of transferability on the main job are more likely to choose the same occupation in their second job
} 
framework. The objective is to base empirical analysis on an internally consistent analytical framework that can capture some salient features of labor supply in both constrained and unconstrained decision environments.

While the choice of any specific utility function is inherently arbitrary, we seek a specification that is sufficiently flexible to accommodate agent heterogeneity in labor supply decisions and at the same time provides a unified treatment of several labor supply regimes encountered in practice. In a simple unitary job framework, there is no ambiguity about expressing the marginal utility of leisure as simply minus one times the marginal disutility of labor supply. The utility function is easily expressed either in terms of leisure (total time available for work and leisure minus labor supply) or in terms of hours of work.

When labor supply arises from more than a single job, there is a need to recognize that the marginal disutility of work can vary across jobs. This is analogous to disaggregating commodities in a utility function. ${ }^{4}$ So the disutility of job 1 may differ from job 2 because jobs are not perfect substitutes. For example, workers can hold a less pleasurable primary job while working on second job that provides some gratification but it is less secure (Conway and Kimmel, 1998). Therefore, aggregating hours worked across all jobs into a single homogenous measure of labor supply is unnecessarily restrictive. If there is heterogeneity in the disutility of marginal hours of work across multiple jobs, it follows that the marginal utility or value of leisure freed up from each job will vary. Hence, it is useful to be able to write the utility function in a way that the marginal utility of leisure freed up from each job is clearly identified. To this end we uniquely adapt a Stone-Geary Utility function model to represent labor supply to more than one job.

The advantage of a Stone-Geary specification is that it specifies upper bounds to labor supply to each job as well as a lower bound to income. Given heterogeneity in the disutility associated with different jobs, the assumption that each job has its own upper bound makes sense. As shown below, the aggregation of these upper bounds yields the upper bound for the total hours available for work and leisure. Satisfaction of these boundary constraints is necessary in order to have a utility function defined in which utility is increasing in income and leisure (decreasing in hours). The marginal utility of leisure (disutility of work) corresponding to each job is easily expressed. The derivations of the labor supply elasticities for the Stone-Geary utility function and their estimated values are presented in a technical appendix available upon request of the

\footnotetext{
${ }^{4}$ In the present context the available price and quantity information is disaggregated for jobs but not for commodities.
} 
authors.

Unconstrained dual job holder

Consider utility maximization for a multiple (dual) job holder who is not constrained in their choice of hours to work at two jobs:

$$
U=\left(\gamma_{1}-h_{1}^{*}\right)^{\alpha_{1}}\left(\gamma_{2}-h_{2}^{*}\right)^{\alpha_{2}}\left(y^{*}-\gamma_{3}\right)^{1-\alpha_{1}-\alpha_{2}}
$$

where $\alpha_{1}, \alpha_{2}, \gamma_{1}, \gamma_{2}, \gamma_{3}>0, h_{m}^{*}$ represents the time allocated to job $m$, and $y^{*}$ is income. The parameters $\gamma_{1}$ and $\gamma_{2}$ represent the upper bounds on the time that can be expended on jobs 1 and 2 , and still have the utility function defined. The total time available for work and leisure $(T)$ is defined by

$$
T=\sum_{m=1}^{2} \gamma_{m} .
$$

The parameter $\gamma_{3}$ represents the lower bound on the amount of income necessary for the utility function to be defined. The terms $\left(\gamma_{m}-h_{m}^{*}\right), m=1,2$ represent the times freed up by each job for leisure consumption. Total consumption of leisure time $\ell$ is residually obtained as

$$
\begin{aligned}
\ell & =T-h_{1}^{*}-h_{2}^{*} \\
& =\gamma_{1}+\gamma_{2}-h_{1}^{*}-h_{2}^{*} \\
& =\left(\gamma_{1}-h_{1}^{*}\right)+\left(\gamma_{2}-h_{2}^{*}\right) .
\end{aligned}
$$

Note that allowing the upper bounds on labor supply to be different for two jobs is necessary for identification. Suppose we were to treat the sum of the individual upper bound limits on labor supply as the overall total hours constraint $\gamma_{h}=\gamma_{1}+\gamma_{2}=T$, so that hours on each job in the utility function would appear as $\left(\gamma_{h}-h_{1}^{*}-h_{2}^{*}\right)^{\alpha_{h}}$. The utility maximization process as described below would impose a restriction that wages have to be equal on both jobs. Consequently, it can be shown that there would only be one equation for the two unknowns $h_{1}^{*}$ and $h_{2}^{*}$. 
The economic problem facing an unconstrained dual job holder can be stated as

$$
\begin{aligned}
\max _{h_{1}, h_{2}, y} U & =\left(\gamma_{1}-h_{1}^{*}\right)^{\alpha_{1}}\left(\gamma_{2}-h_{2}^{*}\right)^{\alpha_{2}}\left(y^{*}-\gamma_{3}\right)^{1-\alpha_{1}-\alpha_{2}} \\
\text { s.t. } y^{*} & =\sum_{m=1}^{2} w_{m} h_{m}^{*}+I, \\
0 & <h_{m}^{*}<\gamma_{m}, m=1,2 \text { and } \\
\sum_{m=1}^{2} h_{m}^{*} & \leq T,
\end{aligned}
$$

where $w_{m}$ is the wage or pecuniary rewards to the $m$ th job, and $I$ is non-labor income. The utility maximizing dual labor supply functions are given by

$$
\begin{aligned}
& h_{1}^{*}=\left(1-\alpha_{1}\right) \gamma_{1}-\alpha_{1} \gamma_{2}\left(\frac{w_{2}}{w_{1}}\right)+\alpha_{1} \gamma_{3}\left(\frac{1}{w_{1}}\right)-\alpha_{1}\left(\frac{I}{w_{1}}\right) \\
& h_{2}^{*}=\left(1-\alpha_{2}\right) \gamma_{2}-\alpha_{2} \gamma_{1}\left(\frac{w_{1}}{w_{2}}\right)+\alpha_{2} \gamma_{3}\left(\frac{1}{w_{2}}\right)-\alpha_{2}\left(\frac{I}{w_{2}}\right) .
\end{aligned}
$$

The second and fourth term in equation (2) and (3) show that the labor supply to each job is always decreasing in both the cross-wage and the non-labor income. The labor supply curve can be upward sloping or backward bending, depending on the sign of the following derivative:

$$
\frac{\partial h_{m}^{*}}{\partial w_{m}}=\frac{\alpha_{m}}{w_{m}^{2}}\left(\gamma_{k} w_{k}+I-\gamma_{3}\right) \gtreqless 0 .
$$

The equivalent earnings versions of dual labor supply may be expressed as

$$
\begin{aligned}
& w_{1} h_{1}^{*}=\alpha_{1} \gamma_{3}+\left(1-\alpha_{1}\right) \gamma_{1} w_{1}-\alpha_{1} \gamma_{2} w_{2}-\alpha_{1} I \\
& w_{2} h_{2}^{*}=\alpha_{2} \gamma_{3}+\left(1-\alpha_{2}\right) \gamma_{2} w_{2}-\alpha_{2} \gamma_{1} w_{1}-\alpha_{2} I .
\end{aligned}
$$

The $\alpha$ parameters of the utility function are of course literally the elasticities of the utility index with respect to the time released for leisure consumption from each job. A more useful interpretation of these parameters can be obtained from the equilibrium conditions. Note that the maximum amount of discretionary income may be defined as

$$
y_{\max }^{*}=\gamma_{1} w_{1}+\gamma_{2} w_{2}+I-\gamma_{3} .
$$


In equilibrium the values for $h_{1}^{*}$ and $h_{2}^{*}$ satisfy the following solutions for $\alpha_{1}$ and $\alpha_{2}$ obtained from equations (4) and (5):

$$
\begin{aligned}
\alpha_{1} & =\frac{\left(\gamma_{1}-h_{1}^{*}\right) w_{1}}{\gamma_{1} w_{1}+\gamma_{2} w_{2}+I-\gamma_{3}} \\
& =\frac{\left(\gamma_{1}-h_{1}^{*}\right) w_{1}}{y_{\max }^{*}}
\end{aligned}
$$

and

$$
\begin{aligned}
\alpha_{2} & =\frac{\left(\gamma_{2}-h_{2}^{*}\right) w_{2}}{\gamma_{1} w_{1}+\gamma_{2} w_{2}+I-\gamma_{3}} \\
& =\frac{\left(\gamma_{2}-h_{2}^{*}\right) w_{2}}{y_{\max }^{*}} .
\end{aligned}
$$

$\alpha_{1}$ and $\alpha_{2}$ represent the shares of maximum discretionary income that are expended on the consumption of leisure arising from working less than the maximum threshold hours. The remaining share is discretionary non-leisure consumption as a share of maximum discretionary income:

$$
\begin{aligned}
1-\alpha_{1}-\alpha_{2} & =1-\frac{\left(\gamma_{1}-h_{1}^{*}\right) w_{1}+\left(\gamma_{2}-h_{2}^{*}\right) w_{2}}{\gamma_{1} w_{1}+\gamma_{2} w_{2}+I-\gamma_{3}} \\
& =\frac{w_{1} h_{1}^{*}+w_{1} h_{2}^{*}+I-\gamma_{3}}{\gamma_{1} w_{1}+\gamma_{2} w_{2}+I-\gamma_{3}} \\
& =\frac{y^{*}-\gamma_{3}}{y_{\max }^{*}} .
\end{aligned}
$$

\section{Unconstrained unitary job holders}

Our framework is based on the reasonable assumption that all job holder types are nested within the same utility function. This allows one to characterize individuals who move back and forth between unitary and dual job holding as responding to changes in their economic environments and avoids the awkwardness of having to assume that these individuals are responding to periodic ad hoc changes in preferences. In fact in terms of Kuhn-Tucker conditions, one can think of the unconstrained unitary job holder as a worker who faces a wage on the second job that is less than the ratio of the marginal disutility from working on the second job to the 
marginal utility of income. ${ }^{5}$

For individuals who hold only one job, we then condition on $h_{2}^{*}=0$ :

$$
\begin{aligned}
\max _{h_{1}, y} U & =\left(\gamma_{1}-h_{1}^{*}\right)^{\alpha_{1}}\left(\gamma_{2}\right)^{\alpha_{2}}\left(y^{*}-\gamma_{3}\right)^{1-\alpha_{1}-\alpha_{2}} \\
\text { s.t. } y & =w_{1} h_{1}^{*}+I \\
0 & <h_{1}^{*}<\gamma_{1}, \\
h_{1}^{*} & \leq T .
\end{aligned}
$$

Labor supply to job 1 in this case can be shown to be

$$
h_{1}^{*}=\left(\frac{1-\alpha_{1}-\alpha_{2}}{1-\alpha_{2}}\right) \gamma_{1}+\left(\frac{\alpha_{1}}{1-\alpha_{2}}\right)\left(\gamma_{3}\right)\left(\frac{1}{w_{1}}\right)-\left(\frac{\alpha_{1}}{1-\alpha_{2}}\right)\left(\frac{I}{w_{1}}\right)
$$

or in terms of earnings,

$$
w_{1} h_{1}^{*}=\left(\frac{1-\alpha_{1}-\alpha_{2}}{1-\alpha_{2}}\right) \gamma_{1} w_{1}+\left(\frac{\alpha_{1}}{1-\alpha_{2}}\right)\left(\gamma_{3}\right)-\left(\frac{\alpha_{1}}{1-\alpha_{2}}\right) I
$$

Note that the interpretation of equation (7) is similar to the interpretation of equation (2) with the exception that the labor supply to job 1 is not a function of a cross wage. However, even if $h_{2}^{*}=0$, the parameter $\alpha_{2}$ still affects labor supply responsiveness on the unitary job. In fact the response to an increase in non-labor income will be always larger for an unconstrained unitary job holder than the reduction in the hours supplied to job 1 for an unconstrained dual job holder. This is expected, as the unconstrained unitary job holder only reduces the hours supplied to one job, while the unconstrained dual job holder will reduce the hours supplied to both jobs in response to an increase in non-labor income.

\section{Constrained dual job holder}

We assume that constraints on labor supply for dual job holders apply only to job 1, i.e. workers are constrained either because they desire more hours on job 1 (underemployed) or they desire fewer hours on job 1 (overemployed). Consequently, constrained dual job holders are assumed to be working their desired hours on job 2 conditional on their constrained hours in job $1 .^{6}$ For an individual who is constrained at $h_{1}=\ddot{h}_{1}$, the utility maximization problem

\footnotetext{
${ }^{5}$ In the empirical section we introduce a multinomial selection process that accounts for the fact that the potential wage on the second job for unitary job holders is unobservable to us.

${ }^{6}$ This assumption is supported by the data. Typically the hours constraint is generated by institutional labor laws which force firms to pay overtime above a certain number of hours worked per week. For the UK this cut off is set
} 
becomes

$$
\begin{aligned}
\max _{h_{2}, y} U & =\left(\gamma_{1}-\ddot{h}_{1}\right)^{\alpha_{1}}\left(\gamma_{2}-h_{2}^{*}\right)^{\alpha_{2}}\left(y^{*}-\gamma_{3}\right)^{1-\alpha_{1}-\alpha_{2}} \\
\text { s.t. } y & =w_{2} h_{2}^{*}+w_{1} \ddot{h}_{1}+I, \\
\quad 0 & \leq h_{2}^{*}<\gamma_{2}, \quad 0 \leq \ddot{h}_{1}<\gamma_{1}, \text { and } \\
\ddot{h}_{1}+h_{2}^{*} & \leq T,
\end{aligned}
$$

While labor supply to job 1 is fixed at $\ddot{h}_{1}$, desired labor supply to job 2 is determined according to

$$
h_{2}^{*}=\left(\frac{1-\alpha_{1}-\alpha_{2}}{1-\alpha_{1}}\right) \gamma_{2}+\left(\frac{\alpha_{2} \gamma_{3}}{1-\alpha_{1}}\right)\left(\frac{1}{w_{2}}\right)-\left(\frac{\alpha_{2}}{1-\alpha_{1}}\right)\left(\frac{w_{1} \ddot{h}_{1}+I}{w_{2}}\right)
$$

In terms of expected earnings, labor supply to job 2 would simply be

$$
w_{2} h_{2}^{*}=\left(\frac{1-\alpha_{1}-\alpha_{2}}{1-\alpha_{1}}\right) \gamma_{2} w_{2}+\left(\frac{\alpha_{2} \gamma_{3}}{1-\alpha_{1}}\right)-\left(\frac{\alpha_{2}}{1-\alpha_{1}}\right)\left(w_{1} \ddot{h}_{1}+I\right) .
$$

Constrained unitary job holder

For a constrained unitary job holder, the hours worked $\left(\ddot{h}_{1}\right)$ are treated as exogenous so there is no corresponding labor supply equation.

\section{Data}

The estimation of our model is conducted using data from the British Household Panel Survey (BHPS). The survey began in 1991 with a sample of some 5,500 household randomly drawn from all areas of Great Britain. To this initial sample, an over-sample of 1,500 households form Scotland and Wales was added in 1999 and a sample of 2,000 households from Northern Ireland was added in 2001. Individuals are followed over time through an annual questionnaire. The survey asked whether in the month preceding the interview the respondent had worked on a second job. The sample is restricted to prime age working men (age 18 to 65) who are not enrolled in school. ${ }^{7}$ In the BHPS the main job for a dual job holder is defined as the job in

at 41 gross hours (36 net hours) per week. Figure 3 reveals that the mode of the distribution of the hours worked on the first job is around the institutional standard hours while the distribution of the hours on the second job is always below that cut off. As such the institutional standard hours seem to be binding for the first job but not for the second job.

${ }^{7}$ We also ran our estimation for the sample of men aged 25 to 65 to avoid the standard problems associated with selection into college. However we obtain results virtually identical to those reported in this paper. Results are 
which one works the most hours.

Importantly for the scope of this study, BHPS contains information about the presence of an hours constraint on the main job. Specifically respondents were asked whether they would have liked to work more, less, or the same hours assuming that they would be paid the same amount per hour. Since this question was asked directly after respondents reported their hours of work on the main job, we interpret the answer to this question as an indicator for an hours constraint on the main job. Accordingly for each type of job holder (unitary or dual) we can identify if he is constrained on the main job. In the end we have 6 possible cases: 1) unitary job holders who work their desired amount of hours on the main job - unconstrained unitary job holders; 2) unitary job holders who would have liked to work more hours on the main job (underemployed); 3) unitary job holders who would have liked to work less hours on the main job (overemployed); 4) dual job holders who work their desired hours on the main job unconstrained dual job holders; 5) dual job holders who are underemployed on their main job; 6) dual job holders who are overemployed on their main job.

While most of the variables are straightforward, some may require explanation about how they were constructed. The gross wage rate was calculated by dividing the monthly earnings by the usual hours worked on the relevant job times four. This procedure was preferred to the selfreported information on the hourly wage rate because it guarantees internal consistency between the estimation of the hours and the earnings equations. To mitigate the effect of outliers, we deleted from our sample individuals who earn less than $£ 1 /$ hour or more than $£ 100 / \mathrm{hr}$. Moreover we drop individuals with reported hours of work outside the 1 to 99 percentile of the distribution of hours worked in the sample. Non-labor income is the sum of all state benefits (including pension), money transfer, and income from rent, saving, and investment.

We determine an individual's marginal income tax rate $\left(\tau_{i t}\right)$ based on the information we have on weekly earnings coupled with the personal tax allowances and tax rate bands in effect in the UK for each year in our sample period. If we let $W_{m i t}$ refer to nominal gross wage rates, the tax-rate adjusted nominal wage rate for each job is simply $\left(1-\tau_{i t}\right) W_{m i t}, m=1,2$. Changes in British tax law after 1993 treat dividend and savings income differently from other forms of nonlabor income. Since we are unable to identify the separate components of non-labor income, we apply the dividend and savings marginal tax rates to the entire amount of non-labor income. If we let $N L I_{i t}$ represent nominal gross non-labor income, the tax-rate adjusted nominal nonavailable from the authors upon request. 
labor income is given by $\left(1-\tau_{i t}^{I}\right) N L I_{i t}$. Our empirical analysis therefore models weekly hours of labor supply as a function of hourly wage rates and non-labor income corrected for inflation and marginal income tax rates.

Real non-labor and total income are measured on a weekly basis. Individual wage rates and non-labor income corrected for inflation and tax rates are calculated according to

$$
\begin{aligned}
w_{m i t} & =\frac{W_{m i t}\left(1-\tau_{i t}^{w}\right)}{P_{t}}, m=1,2 \\
I_{i t} & =\frac{\left(1-\tau_{i t}^{I}\right) N L I_{i t}}{P_{t}}
\end{aligned}
$$

where $P_{t}$ is a cost of living deflator for period $t^{8}$

Table 2 reports means and standard deviations for variables in our analyses. After excluding observations with missing data for any variables in the models, we are left with a total of 44,921 observations. We have complete information on dual job holder observations in 2,785 cases, which account for about $6 \%$ of all the observations in our estimation sample. Almost $60 \%$ of dual job holding episodes are associated with no hours constraints on the main job; another $31 \%$ of the dual job holding episodes is associated with workers who are overemployed on the main job, and the remaining $9 \%$ of dual job holding episodes is associated with workers who are underemployed on the main job. This last result indicates that the usual explanation for holding two jobs, i.e. the need to fulfill an unmet hours target on the main job, does not seem to fit well with the stylized facts in the UK. ${ }^{9}$ Moreover, the underemployed hours (constrained) model cannot explain why so many dual job holders actually desired to work less hours on the main job: if a worker is overemployed on the main job, why would he take a second job? The job portfolio model offers a reasonable explanation for this finding. Jobs are heterogeneous for a variety of reasons and that is why some workers prefer to allocate their desired hours of work over a portfolio of jobs. Long contractual hours on the main job may actually bring a worker above the desired equilibrium hours of work. Although the portfolio model seems to better serve the stylized facts in the UK, one cannot disregard that only 6 percent of the sample of unitary job episodes consider themselves underemployed. This is somewhat lower than the incidence of underemployment among dual job holders, thus suggesting that individuals do take a second

\footnotetext{
${ }^{8}$ Our adjustment for taxes is a simple approximation that treats marginal rates as proportional in order to obtain local after tax wage rates and income. Hence, our analysis does not attempt to incorporate the kinked budget arising from a graduated income tax system.

${ }^{9}$ This conclusion is in line with the results in Wu et al. (2009) although their argument is based on the fact that the wage on job 2 is larger than the wage on job 1.
} 
job in response to a situation of underemployment on the main job.

Not surprisingly, we find that underemployed individuals work less hours on the main job than unconstrained workers while overemployed individuals work more hours on the main job than unconstrained workers. Conditional on being constrained, on average dual job holders work less hours on their main job, but after adding the hours supplied on the second job, dual job holders work more total hours per week.

Among unitary job holders, hours are more dispersed for those who are constrained. Correcting for different mean hours by calculating the coefficient of variation shows that the relative dispersion in hours among the underemployed (0.24) is higher than for the unconstrained unitary job holders (0.19). For the overemployed the relative dispersion in hours is the same as for the unconstrained unitary job holders. In the case of dual job holders, the absolute hours dispersion on job 1 is higher among the constrained workers. For underemployed workers, the relative hours dispersion is higher $(0.28)$ than that of unconstrained dual job holders $(0.21)$. On the other hand the relative hours dispersion for overemployed dual job holders is marginally lower $(0.20)$ than that of the unconstrained workers. Compared with job 1, the absolute hours dispersion is much less on job 2. This is also seen in the hours densities shown in Figure 3. However, the relative hours dispersion is much higher on job 2 for both constrained and unconstrained dual job holders. Among unconstrained dual job holders, the standard deviation is $86 \%$ of the mean. The relative hours dispersions are less on job 2 for constrained dual job holders, $83 \%$ and $84 \%$ for underemployed and overemployed dual job holders, respectively. This suggests the existence of considerable hours flexibility on the second job.

The average hourly wage on the main job for unitary job holders is higher than for dual job holders. For dual job holders, the hourly wage rate on the second job is higher than on the main job, although the weekly earnings on the main job are higher because individuals work more hours on the main job. Neither the portfolio nor the constrained labor supply regimes impose any restrictions on the relative magnitudes of the rates of pay between the two jobs. Compared with their unconstrained fellow workers, the average hourly wage of underemployed workers is lower and the average hourly wage of overemployed workers is higher.

Unitary and dual job holders differ on a number of socioeconomic dimensions. For example, dual job holders tend to be younger than unitary job holders and less likely to be married. Moreover, underemployed workers (both unitary and dual job holders) seem to be less educated than the other two classes of workers: only $19 \%$ of underemployed unitary job holders and $17 \%$ 
of underemployed dual job holders have some degree above the A level. ${ }^{10}$ This rate is higher for overemployed workers (both unitary and dual job holders) at $29 \%$. Hence, it could well be that some underlying selection process determines whether a workers falls into one of the six categories in a systematic way.

Table 3 reports an unconditional transition probability matrix over the period of our study. We add a row and column corresponding to moving into the sample from out of the sample and moving out of the sample from within the sample, where "'out of sample"' indicates that the respondent is not working or due to the unbalanced design was not in the sample. For any given period, those with the highest probability of moving out of the sample the next period were overemployed dual job holders with a probability of 0.29 . On the other hand, among those who move into the sample in any given period, the probability is the highest $(0.55)$ that they would fall into the category of unconstrained unitary job holders. While the probability of remaining in one's current regime exceeds the probabilities of moving to any other labor supply regime for most regimes, two exceptions are found among underemployed workers. For example the probabilities that unitary and dual job underemployed workers would transition in the next period to being unconstrained unitary job holders are 0.38 and 0.20 versus remaining in the same regimes with probabilities 0.22 and 0.12 , respectively. Other noteworthy transitions are unconstrained unitary job holders becoming overemployed unitary job holders with probability 0.17 and overemployed unitary job holders transitioning to unconstrained unitary job holders with probability 0.26 . Similarly, the probability is 0.20 that an unconstrained dual job holder would transition to an unconstrained unitary job holder. These are of course raw transitions, but they point to the desirability of specifying a single unifying utility function for workers across all labor supply outcomes. In the empirical model below we treat the placement of workers into labor supply regimes as the result of a multinomial logit selection process with unobserved heterogeneity. ${ }^{11}$

\section{Empirical Model}

In this section we present the empirical model used to estimate the labor supply elasticities. We also describe how we control for the sample selection mentioned in the previous section within

\footnotetext{
${ }^{10}$ 'A' level education represents 13 years of education/upper secondary school.

${ }^{11}$ An alternative modeling strategy to sample selection would be nested logit. Conditional on whether or not one is constrained on their first job, an individual chooses between holding one job and holding two jobs. One challenge is that with our data it would be difficult to find plausible variables reflecting choice specific characteristics.
} 
our panel data. The estimation will be carried out using MLE. To introduce the stochastic element in the model, one can think of $w_{m} h_{m}^{*}$ and $y^{*}$ as planned earnings and income. The relationship between actual labor supply earnings, $w_{m} h_{m}$ from job $m$, and planned earnings, $w_{m} h_{m}^{*}$, is given by $w_{m} h_{m}=w_{m} h_{m}^{*}+v_{m}$, where $v_{m}$ is a random error term. The relationship between actual income, $y$, and planned income, $y^{*}$, may be expressed as $y^{*}=y-v_{y}$, where $y=\sum_{m=1}^{2} w_{m} h_{m}+I$. Note that we can solve for $v_{y}$ from

$$
\begin{aligned}
v_{y} & =y-y^{*} \\
& =\left(\sum_{m=1}^{2} w_{m} h_{m}+I\right)-\left(\sum_{m=1}^{2} w_{m} h_{m}^{*}+I\right) \\
& =\sum_{m=1}^{2} w_{m}\left(h_{m}-h_{m}^{*}\right) \\
& =\sum_{m=1}^{2} v_{m} .
\end{aligned}
$$

Because constrained hours on job 1 are treated as exogenous, we do not estimate job 1 labor supply functions in these cases. This leaves us with five labor supply functions to estimate that span four selection regimes: $h_{1}$ and $h_{2}$ for unconstrained dual job holding - case (1), $h_{1}$ for unconstrained unitary job holding - case (2), $h_{2}$ for underemployed dual job holders on job 1 - case (3), and $h_{2}$ for overemployed dual hob holders on job 1 - case (4). Hours are measured as hours per week, wages are measured as hourly wage rates, and non-labor and total income are measured on a weekly basis. All monetary variables are expressed in terms of 2008 prices. Following Renna et al. (2013), our empirical estimation is conducted for the earnings version of the Stone-Geary labor supply model.

Our analysis extends the sample selection approaches of Lee (1983), Wooldridge(1995; 2010), and Dustmann and Rochina-Barrachina (2007) to multivariate selection in a panel data setting. The first stage of our panel data estimation of the dual labor supply model is estimation of a pooled multinomial logit that allows for correlated random effects. Let $s_{i t}$ represent a variable that assumes the values $0,1, \ldots, 5$ corresponding to the six job holding outcomes. We can equivalently define indicator variables corresponding to these six labor supply outcomes: $s_{i t j}=1\left[s_{i t}=j\right]$. Following Wooldridge (2010, pp.653-654), we assume that $P\left(s_{i t}=j \mid x_{i t}, c_{i}\right)=P\left(s_{i t}=j \mid x_{i}, c_{i}\right), j=0,1, \ldots, 5$, where $x_{i t}$ is a vector of the explanatory variables (which can include time invariant variables), $x_{i}$ is the vector of the means of the 
variables $x_{i t}$ for the $i$ th individual, and $c_{i}$ is unobserved heterogeneity. A simplifying assumption that permits averaging out of the $c_{i}$ terms is that $P\left(s_{i t}=j \mid x_{i}\right)=P\left(s_{i t}=j \mid x_{i t}, \bar{\omega}_{i}\right)$, where $\bar{\omega}_{i}$ is a vector of means of the variables in $x_{i t}$ that are either time-varying or time-invariant.

The universally available variables for our model are specified by

$$
\begin{aligned}
x_{i t} & =\left(1, w_{1 i t}, I_{i t}, \mathrm{Age}_{i t}, \mathrm{Educ}_{i t}, \mathrm{MS}_{i t}, \mathrm{DP}_{i t}, \mathrm{Year}_{i t}\right) \\
\bar{\omega}_{i} & =\left(\bar{w}_{1 i}, \bar{I}_{i}, \overline{\operatorname{Age}}_{i}, \overline{\operatorname{Educ}}_{i}, \overline{\mathrm{MS}}_{i}, \overline{\mathrm{DP}}_{i}, \overline{\mathrm{Year}}_{i}\right),
\end{aligned}
$$

where Age is the individual's age, Educ is a vector of educational attainment dummy variables, MS is marital status (= 1 if married), DP is the number of dependent children, and Year is a set of year indicator variables. Given the above assumptions, our multinomial logit selection model generates probabilities according to

$$
\begin{aligned}
P_{j i t} & =P\left(s_{i t}=j \mid x_{i t}, \bar{\omega}_{i}\right), j=1, \ldots, 5 \\
& =\Lambda\left(x_{i t}, \bar{\omega}_{i}, \beta_{j}\right) \\
P_{0 i t} & =1-\sum_{j=1}^{5} P_{i j t},
\end{aligned}
$$

where $\beta_{j}$ is the multinomial logit parameter vector for outcome $j$.

Let $z_{j i t}=\Phi^{-1}\left(P_{j i t}\right)$, where $\Phi^{-1}$ is the inverse standard normal CDF. It is clear that $\Phi\left(z_{j i t}\right)=P_{j i t}=\Lambda\left(x_{i t}, \bar{\omega}_{i}, \beta_{j}\right)$. Accordingly, we construct the appropriate Inverse Mill Ratio (IMR) variables $\lambda_{j i t}=\frac{\phi\left(z_{j i t}\right)}{\Phi\left(z_{j i t}\right)}$ that will be added as regressors in the five labor supply equations. Since, when using a structural model, the demographic variables do not enter the labor supply directly, our modeling choice also ensures that the system is identified. In fact, except for $w_{1 i t}$ and $I_{i t}$, the demographic variables in $x_{i t}$ used to estimate IMR do not appear in the labor supply equations.

We estimate the Stone-Geary model's boundary parameters $\gamma_{1}, \gamma_{2}$, and $\gamma_{3}$ directly from our panel data sample. Let $\tilde{\gamma}_{1}$ be the highest integer value that satisfies $h_{1}^{\max }<\tilde{\gamma}_{1} \leq 1+h_{1}^{\max }$ for the combined samples for all workers who work job 1 over all periods; let $\tilde{\gamma}_{2}$ be the highest integer value that satisfies $h_{2}^{\max }<\tilde{\gamma}_{2} \leq 1+h_{2}^{\max }$ for the combined samples for all workers who work job 2 over all periods; and let $\tilde{\gamma}_{3}$ be the lowest integer value that satisfies $y^{\text {min }}-1 \leq \tilde{\gamma}_{3}<y^{\text {min }}$ for the combined samples for all workers over all periods, where $h_{m}^{\max }$ is the maximum observed hours of work for job $m$ and $y^{\text {min }}$ is the lowest observed income. 
Let $v_{m l i t}$ represent the sum of an unobserved individual effect for labor supply and an idiosyncratic error term, where $m=1,2$ for job 1 or job $2, l=1,2,3,4$ indexes the four labor supply selection regimes, $i=1, \ldots, n$, and $t=1, \ldots, T$. The error structure for each labor supply regime can be characterized by (see Wooldridge 2010, pp.832-837)

$$
v_{m l i t}=\theta_{m l} \lambda_{m l i t}+\bar{Z}_{l i} \pi_{m l}+u_{m l i t}
$$

where $\bar{Z}_{l i}$ is a vector of time averaged variable means for all individuals in regime $l, \pi_{m l}$ is a conforming parameter vector, $u_{m l i t}=v_{m l i}-E\left(v_{m l i t} \mid q_{m l i t}, \lambda_{m l i t}, \bar{Z}_{l i}\right)$, and $q_{m l i t}$ is a labor supply variable (defined below) arising from maximization of the Stone-Geary utility function.

The labor supply equations are jointly estimated by pooled, non-linear Seemingly Unrelated Regressions (SUR) with cross-equation restrictions on the parameters $\alpha_{1}$ and $\alpha_{2}$. In practice the Inverse Mills Ratios (IMR's) are replaced by their estimated values $\hat{\lambda}_{m l i t}$ obtained from the multinomial logit model and the standard errors are bootstrapped. ${ }^{12}$ The labor supply elasticities based on the estimated model will include not only those arising from the Stone-Geary utility function but also those that involve the selection terms and unobserved heterogeneity. In order to focus only on local period effects of marginal changes in wage rates and non-labor income, we hold constant the time averaged sample means of these variables.

The empirical labor supply functions are specified below. ${ }^{13}$

Unconstrained dual job holders

$$
\begin{aligned}
& w_{1 i t}\left(h_{1 i t}-\tilde{\gamma}_{1}\right)=\alpha_{1} q_{1 i t}+\theta_{11} \hat{\lambda}_{1 i t}+\bar{Z}_{1 i} \pi_{11}+u_{11 i t} \\
& w_{2 i t}\left(h_{2 i t}-\tilde{\gamma}_{2}\right)=\alpha_{2} q_{1 i t}+\theta_{21} \hat{\lambda}_{1 i t}+\bar{Z}_{1 i} \pi_{21}+u_{21 i t},
\end{aligned}
$$

where

$$
\begin{aligned}
q_{11 i t} & =q_{21 i t}=q_{1 i t} \\
& =\tilde{\gamma}_{3}-\tilde{\gamma}_{1} w_{1 i t}-\tilde{\gamma}_{2} w_{2 i t}-I_{i t},
\end{aligned}
$$

\footnotetext{
${ }^{12}$ Estimated standard errors reported in the paper are bootstrap estimates from 200 replications that account for all estimation steps, including the estimation of multinomial logit regression and boundary parameters.

${ }^{13}$ For the sample mean values used to correct for unobserved heterogeneity in the labor supply equations, we average only over the time-series for which the individual was in the particular labor supply regime.
} 


$$
\bar{Z}_{1 i}=\left(\bar{w}_{1 i}, \bar{w}_{2 i}, \bar{I}_{i}, \overline{\operatorname{Age}}_{i}, \overline{\operatorname{Educ}}_{i}, \overline{\operatorname{MS}}_{i}, \overline{\mathrm{DP}}_{i}, \overline{\operatorname{Year}}_{i}\right),
$$

and $\pi_{11}$ and $\pi_{21}$ are the corresponding parameter vectors.

The implied hours equation for job 1 from the estimated earnings equation (11) is given by

$$
\hat{h}_{1 i t}=\left(1-\hat{\alpha}_{1}\right) \tilde{\gamma}_{1}+\hat{\alpha}_{1}\left(\frac{\tilde{\gamma}_{3}-\tilde{\gamma}_{2} w_{2 i t}-I_{i t}}{w_{1 i t}}\right)+\hat{\theta}_{11} \frac{\hat{\lambda}_{1 i t}}{w_{1 i t}}+\frac{\bar{Z}_{1 i} \hat{\pi}_{11}}{w_{1 i t}} .
$$

$\underline{\text { Unconstrained unitary job holders }}$

$$
w_{1 i t}\left(h_{1 i t}-\tilde{\gamma}_{1}\right)=\left(\frac{\alpha_{1}}{1-\alpha_{2}}\right) q_{12 i t}+\theta_{12} \hat{\lambda}_{2 i t}+\bar{Z}_{2 i} \pi_{12}+u_{12 i t}
$$

where

$$
\begin{gathered}
q_{12 i t}=\tilde{\gamma}_{3}-\tilde{\gamma}_{1} w_{1 i t}-I_{i t} \\
\bar{Z}_{2 i}=\left(\bar{w}_{1 i}, \bar{I}_{i}, \overline{\operatorname{Age}}_{i}, \overline{\operatorname{Educ}}_{i}, \overline{\mathrm{MS}}_{i}, \overline{\mathrm{DP}}_{i}, \overline{\mathrm{Year}}_{i}\right),
\end{gathered}
$$

and $\pi_{12}$ is the corresponding parameter vector.

The implied hours equation for an unconstrained unitary job holder is obtained from the estimated earnings equation (14):

$$
\left.\hat{h}_{1 i t}\right|_{h_{2}=0}=\left(\frac{1-\hat{\alpha}_{1}-\hat{\alpha}_{2}}{1-\hat{\alpha}_{2}}\right) \tilde{\gamma}_{1}-\left(\frac{\hat{\alpha}_{1}}{1-\hat{\alpha}_{2}}\right)\left(\frac{I_{i t}-\tilde{\gamma}_{3}}{w_{1 i t}}\right)+\hat{\theta}_{12} \frac{\hat{\lambda}_{2 i t}}{w_{1 i t}}+\frac{\bar{Z}_{2 i} \hat{\pi}_{12}}{w_{1 i t}} .
$$

Constrained dual job holders

Constrained dual job holders desiring either fewer or more hours:

$$
\begin{gathered}
w_{2 i t}\left(h_{2 i t}-\tilde{\gamma}_{2}\right)=\left(\frac{\alpha_{2}}{1-\alpha_{1}}\right) q_{2 i t}+\theta_{23} \hat{\lambda}_{23 i t}+\bar{Z}_{3 i} \pi_{23}+u_{23 i t} \text { (overemployed) } \\
w_{2 i t}\left(h_{2 i}-\tilde{\gamma}_{2}\right)=\left(\frac{\alpha_{2}}{1-\alpha_{1}}\right) q_{2 i t}+\theta_{24} \hat{\lambda}_{24 i t}+\bar{Z}_{3 i} \pi_{24}+u_{24 i t} \text { (underemployed) }
\end{gathered}
$$

where

$$
\begin{aligned}
q_{23 i t} & =q_{24 i t}=q_{2 i t} \\
& =\tilde{\gamma}_{3}-\tilde{\gamma}_{2} w_{2 i t}-\left(w_{1 i t} \ddot{h}_{1 i t}+I_{i t}\right),
\end{aligned}
$$




$$
\begin{aligned}
\bar{Z}_{3 i} & =\left(\bar{w}_{2 i},{\overline{w_{1 i}}}_{\ddot{h}_{1 i}}, \bar{I}_{i}, \overline{\mathrm{Age}}_{i}, \overline{\operatorname{Educ}}_{i}, \overline{\mathrm{MS}}_{i}, \overline{\mathrm{DP}}_{i}, \overline{\mathrm{Year}}_{i}\right) \text { (overemployed), } \\
\bar{Z}_{4 i} & =\left(\bar{w}_{2 i},{\overline{w_{1 i} \ddot{h}_{1 i}}}_{\bar{I}}, \overline{\mathrm{Age}}_{i}, \overline{\mathrm{Educ}}_{i}, \overline{\mathrm{MS}}_{i}, \overline{\mathrm{DP}}_{i}, \overline{\text { Year }}_{i}\right) \text { (underemployed), }
\end{aligned}
$$

$\ddot{h}_{1 i t}$ is the constrained hours on job 1 , and $\pi_{23}$ and $\pi_{24}$ are the corresponding parameter vectors.

For overemployed workers the implied hours equation for job 2 is obtained from the estimated earnings equation (16):

$$
\left.\hat{h}_{2 i t}\right|_{h_{1}=\ddot{h}_{1}>h_{1}^{*}}=\left(\frac{1-\hat{\alpha}_{1}-\hat{\alpha}_{2}}{1-\hat{\alpha}_{1}}\right) \tilde{\gamma}_{2}-\left(\frac{\hat{\alpha}_{2}}{1-\hat{\alpha}_{1}}\right)\left(\frac{w_{1 i t} \ddot{h}_{1 i t}+I_{i t}-\tilde{\gamma}_{3}}{w_{2 i t}}\right)+\frac{\hat{\theta}_{23} \hat{\lambda}_{23 i t}}{w_{2 i t}}+\frac{\bar{Z}_{3 i} \hat{\pi}_{23}}{w_{2 i t}} .
$$

For underemployed workers the implied hours equation for job 2 is obtained from the estimated earnings equation (17) as

$$
\left.\hat{h}_{2 i t}\right|_{h_{1}=\ddot{h}_{1}<h_{1}^{*}}=\left(\frac{1-\hat{\alpha}_{1}-\hat{\alpha}_{2}}{1-\hat{\alpha}_{1}}\right) \tilde{\gamma}_{2}-\left(\frac{\hat{\alpha}_{2}}{1-\hat{\alpha}_{1}}\right)\left(\frac{w_{1 i t} \ddot{h}_{1 i t}+I_{i t}-\tilde{\gamma}_{3}}{w_{2 i t}}\right)+\hat{\theta}_{24} \hat{\lambda}_{24 i t}+\bar{Z}_{4 i} \hat{\pi}_{24} \text {. }
$$

\section{Empirical Results}

Table 4 reports the panel data multinomial logit model of selection into the six mutually exclusive labor supply regimes. Unconstrained unitary job holding is the reference labor supply outcome. Increases in the wage rate on job 1 lower the odds that one would find themselves in any labor supply situation other than being an unconstrained unitary job holder, though only in the case of underemployed unitary job holders does this wage effect fail to achieve statistical significance. Age effects go in the same direction as the job 1 wage effects but age is statistically significant only for being an underemployed unitary job holder. Number of children has a positive and statistically significant effect on the odds of being a constrained dual job holder, with the effect over twice as high for being underemployed compared with being overemployed. Both higher educational (1st degree) and lower educational (Certificate of Secondary Education) attainments reduce the odds of being an underemployed dual job holder relative to being an unconstrained unitary job holder. The main effects of being married are to raise the odds of being an overemployed unitary job holder and lower the odds of being an unconstrained dual job holder. Although not reported in Table 4, the time averaged covariates and year indicator 
variables were generally statistically significant in the estimated panel data multinomial logit model.

Estimates of the basic parameters of the labor supply model are reported in Table 5. As would be expected the boundary hours parameter for the second job (26 hours per week) is much less than on the main job ( 81 hours per week). ${ }^{14}$ The estimated values of $\alpha_{1}$ and $\alpha_{2}$ satisfy theoretical restrictions, i.e. they are positive and bounded on the unit interval. Furthermore, $\hat{\alpha}_{2}>\hat{\alpha}_{1}$ implies that for a dual job holder utility is more responsive to changes in time not spent working on job 2 than to changes in time not spent working on job 1. In other words, leisure associated with reduced hours on the second job yields higher marginal utility than leisure associated with reduced hours on the main job. This result follows directly from our model set up. The definition of job 1 as the job with the longest hours worked together with the finding that the average wage on job 2 is larger than the average wage on job 1 imply that the disutility from job 2 is larger than the disutility from job 1. In light of this conclusion, one could interpret our model as one in which job 1 is the job that yields the smaller disutility of work.

This additional interpretation adds an intrinsically appealing feature to our model. In fact, one could think of at least three different definitions of job 1: (1) the job with the longest hours of work; (2) the job with the highest wage; and (3) the job with the highest weekly earnings. Choosing one definition over another will affect which observations are used in the estimation of the model. This is particularly important for individuals who fall under the job portfolio model, as in this case there is no a priori criterion for which job should be classified job 1 (for the constrained case, job 1 should be the only job the respondent would hold if the constraint were to be lifted). The advantage of adopting the definition of job 1 as the job with the most hours of work is that it is consistent with the assumption that job 1 is the job with the lower disutility of work. Only two of the five IMR $\theta$ parameter estimates are statistically significant. Individuals who are selected into working as unconstrained unitary job holders are types who have a propensity to work more hours. Those who are selected into working as unconstrained dual job holders are types who in job 2 have a propensity to earn more which means to work more hours given the assumption of exogeneity of wage rates for job 2. For the remaining labor supply regimes, we find no evidence of selection bias.

\footnotetext{
${ }^{14}$ As a robustness check, we trimmed the top 1 percent of the sample hours distribution in order to change our hours boundary parameters. Overall, the changes in the boundary values are small to nonexistent. Although the sign changes on the total own wage elasticity on the second job for underemployed dual job holders, this does not alter the conclusion that labor supply to the second job is very inelastic for this class of workers
} 
In Table 6 we report the estimated labor supply elasticities evaluated at the sample specific mean values of the variables corresponding to each of the labor supply regimes. Theoretical restrictions on the labor supply elasticities are satisfied in every case. There are no theoretical predictions for uncompensated own wage elasticities, but these turn out to be positive without exception. Because the substitution effects dominate the income effects, there is no incidence of backward bending Stone-Geary labor supply curves at the mean. In the case of unconstrained unitary job holders, the income effect largely offsets the substitution effect so that the uncompensated labor supply elasticity is quite small. While allowing for selection and unobserved heterogeneity reverses the sign of the the own wage elasticity for unconstrained unitary job holders, it remains quite small and economically insignificant. Among dual job holders (both constrained and unconstrained), the labor supply elasticities for the second job are much larger in absolute value than those associated with the main job for unconstrained dual job holders. The total labor supply elasticities associated with job 2 are noticeably smaller than the inflated Stone-Geary labor supply elasticities. For example, the Stone-Geary own wage labor supply elasticities on the second job for dual job holders range from 5.1 to 7.30 while the total own wage elasticities range from -0.071 to 0.914 .

To have a sense of the magnitudes of the effects on weekly labor supply suggested by our total elasticity estimates, we consider the effects of $10 \%$ changes in wage rates and non-labor income. We use as a base the predicted weekly labor supply for representative workers at sample mean values for each labor supply regime. These results are reported in Table $7 .{ }^{15}$ Despite the nonlinear nature of our empirical labor supply model, the predicted weekly labor supply for each job in each regime correspond fairly closely to the sample means presented in Table 2.

In the case of an unconstrained unitary job holder, the predicted work week is 43 hours. As can be seen from Table 7, the labor supply effects are negligible for this type of worker. Among dual job holders the labor supply effects of changes in the wages for job 2 and non-labor income are also negligible. However, wage changes on the main job can still exhibit quite noticeable impacts on labor supply. First consider an unconstrained dual job holder. Our representative worker is predicted to work 42 hours a week on the main job and 5 hours a week on the second job for a total labor supply of 47 hours per week. A $10 \%$ rise in the wage rate for job 1 is predicted to increase weekly labor supply to job 1 by 2.4 hours and reduce labor supply to job

\footnotetext{
${ }^{15}$ Our predicted weekly labor supply responses reflect the direct effects of changes in the wage rate for job 1 and non-labor income on the probability of switching between regimes. In this application, however, we can consider only their effects on expected labor supply within a labor supply regime.
} 
2 by 3.6 hours for a net reduction in the workweek of 1.2 hours. In the case of dual job holders who are constrained on their labor supply to job 1 , wages on the main job have no impact on the constrained hours for job 1 and only income effects for labor supply to job 2 . For the dual job holder who is working more than their desired hours on job 1 (overemployed), the predicted labor supply to job 2 is 3.7 hours per week. A $10 \%$ increase in the wage for the main job would reduce labor supply to job 2 (and hence total weekly labor supply) by 2.2 hours. In the case of a dual job holder who is working less than their desired hours on job 1 (underemployed), predicted labor supply to job 2 is 6.7 hours per week. A $10 \%$ increase in the wage on the main job would reduce labor supply to job 2 (and hence total weekly labor supply) by 3.2 hours.

\section{Summary and Conclusion}

Using a Stone-Geary utility function we derive a more general model of labor supply that allows for workers to take on a second job. Our model is general in the sense that the reason for holding two jobs is not restricted to an hours constraint on the main job. We adopt the weekly earning version of our model because it consistently dominates the hours version of labor supply in our earlier investigations. For the estimation we use data from the BHPS, a unique data set that contains not only information about the second job, but also information about the hours constraint on the main job. We take advantage of the panel nature of this data set and seek to model unobserved heterogeneity by extending Wooldridge (2010) to a multinomial logit selection equation.

From the results of our earnings equations, we compute both the Stone-Geary labor supply elasticities and the total elasticities that incorporate the effects of sample selection and unobserved heterogeneity. Taking account of the labor supply effects of sample selection and unobserved heterogeneity yields total labor supply elasticities that are generally much smaller for job 2 compared with the corresponding Stone-Geary elasticities. When considering job 2 elasticities versus those for job 1 among unconstrained dual job holders, our findings support the argument that job 2 is the marginal job and, as such, the hours supplied to job 2 should be more responsive to changes.

In general, our results are consistent with previous work based on the same dataset. Similar to Wu et al. (2009) we found that the labor supply curve for job 2 is upward sloping. However, since we jointly estimate the labor supplies of all jobs held by a worker, we can also determine 
the effects of wage and nonlabor income changes on total hours of work. We conclude that although the own substitution effect dominates the income effect within a given job, the effect of a wage change on total hours of work is of the opposite sign. For example, a $10 \%$ rise in the wage rate for job 1 of an unconstrained dual job holder is predicted to increase weekly labor supply to job 1 by 2.4 hours but reduce labor supply to job 2 by 3.6 hours for a net reduction in the workweek of 1.2 hours.

Our study points to some interesting and important considerations for both policy and individual decision making. During business cycle fluctuations there are numerous margins of adjustment including labor supply responses. Among the latter, dual job holding is an alternative to asset decummulation during cyclical downturns. However, we find evidence of stickiness in job holding transitions. For example, unitary and dual job holders are not very likely to switch out of their respective states. This is particularly true for unconstrained workers (both unitary and dual). Constrained job holders are relatively more likely to move to unconstrained status from their disequilibrium job holding status. While our research does not speak directly about the issue of moonlighting as a strategy to stay out of poverty, future research should analyze this important issue.

Without taking account of sample selection, one would have a misleading understanding of labor supply responses to changes in the basic economic drivers of labor supply. For example we show that estimated labor supply responses can even change sign when the full sample selection effects of changes in socio-economic variables are included.

Two interesting generalizations of our model of dual job labor labor supply would be to a) incorporate joint labor supply decisions for all adult members of the household, and b) to investigate dynamic processes in which job hedging considerations are separated out from the job portfolio motive. However, the data and modeling demands of such approaches go well beyond the scope of our initial treatment of multiple job holding. 


\section{References}

Abdukadir, G. (1992). Liquidity constraints as a cause of moonlighting. Applied Economics, 24(12):1307-1310.

Allen, D. W. (1998). The moonlighting decision of unmarried men and momen: Family and labor market influences. Atlantic Economic Journal, 26(2):190-205.

Altonji, J. and Paxson, C. (1988). Labor supply preferences, hours constraints, and hours-wage trade-offs. Journal of Labor Economics, 6(2):254-276.

Averett, S. (2001). Moonlighting: Multiple motives and gender differences. Applied Economics, 33(11):1391-1410.

Bell, D., Hart, R., and Wright, R. (1997). Multiple job holding as a'hedge'against unemployment. CEPR Discussion Papers.

Böheim, R. and Taylor, M. P. (2004). And in the Evening She's a Singer with the Band - Second Jobs, Plight or Pleasure? IZA Discussion Papers 1081, Institute for the Study of Labor (IZA).

Chung, J. (1994). Utility and Production Punctions: Theory and Applications. Blackwell Oxford.

Conway, K. S. and Kimmel, J. (1998). Male labor supply estimates and the decision to moonlight. Labour Economics, 5(2):135-166.

Dustmann, C. and Rochina-Barrachina, M. (2007). Selection correction in panel data models: An application to the estimation of females' wage equations. The Econometrics Journal, 10(2):263-293.

Foley, M. (1997). Multiple job holding in Russia during economic transition. Economic Growth Center Working Papers No 781.

Frederiksen, A., Graversen, E., and Smith, N. (2008). Overtime work, dual job holding, and taxation. Research in Labor Economics, 28:25-55.

Kimmel, J. and Conway, K. S. (2001). Who moonlights and why? Evidence from the SIPP. Industrial Relations: A Journal of Economy and Society, 40(1):89-120. 
Krishnan, P. (1990). The economics of moonlighting: A double self-selection model. The Review of Economics and Statistics, 72(2):361-367.

Lee, L.-F. (1983). Generalized econometric models with selectivity. Econometrica, 51(2):50712.

Lundborg, P. (1995). Job amenity and the incidence of double work. Journal of Economic Behavior \& Organization, 26(2):273 - 287.

Office for National Statistics (2002). Labour market trends. Technical Report 110(10): S18.

Panos, G. A., Pouliakas, K., and Zangelidis, A. (2011). Multiple job holding as a strategy for skills diversification and labour market mobility. Essex Business School, University of Essex.

Paxson, C. and Sicherman, N. (1998). The Dynamics of Dual-Job Holding and Job Mobility. Journal of Labor Economics, 14(3):357-393.

Perlman, R. (1966). Observations on overtime and moonlighting. Southern Economic Journal, 33(2):237-244.

Renna, F., Oaxaca, R. L., and Choe, C. (2013). Constrained vs Unconstrained Labor Supply: The Economics of Dual Job Holding. LISER Working Paper Series 2013-03, LISER.

Shishko, R. and Rostker, B. (1976). The economics of multiple job holding. The American Economic Review, 66(3):298-308.

Theisen, T. (2009). Multiple-job-holding in tanzania. In Kanbur, R. and Svejnar, J., editors, Labor Markets and Economic Development, pages 176-196. Routledge.

Wooldridge, J. (1995). Selection corrections for panel data models under conditional mean independence assumptions. Journal of Econometrics, 68(1):115-132.

Wooldridge, J. (2010). Econometric Analysis of Cross Section and Panel Data. The MIT Press.

Wu, Z., Baimbridge, M., and Zhu, Y. (2009). Multiple job holding in the united kingdom: Evidence from the british household panel survey. Applied Economics, 41(21):2751-2766. 
Figure 1: Rate of Dual-Job Holding among Paid Employees

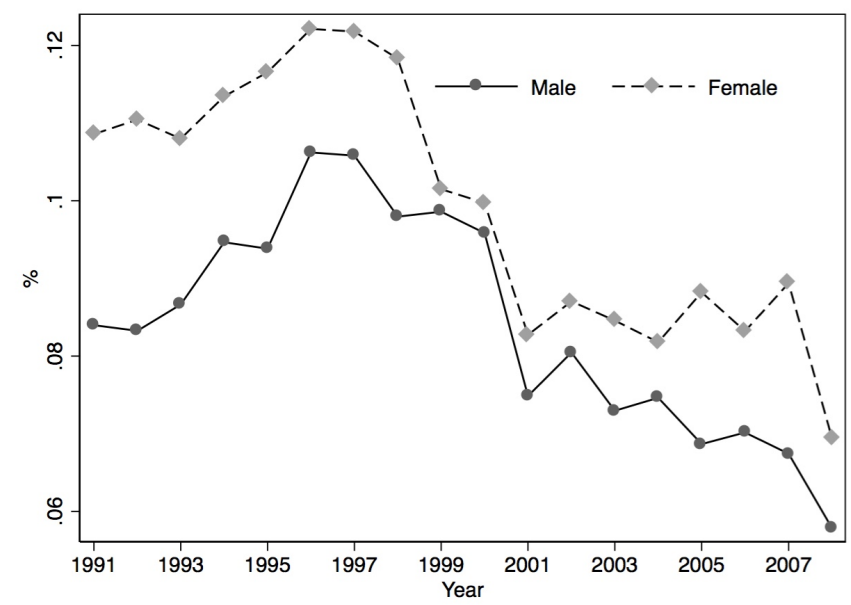

Notes: Rates based on a sample from the

British Household Panel Survey (1991-2008) restricted to individuals aged 18 to 65.

Figure 2: Rate of Dual-Job Holding among Self-employed

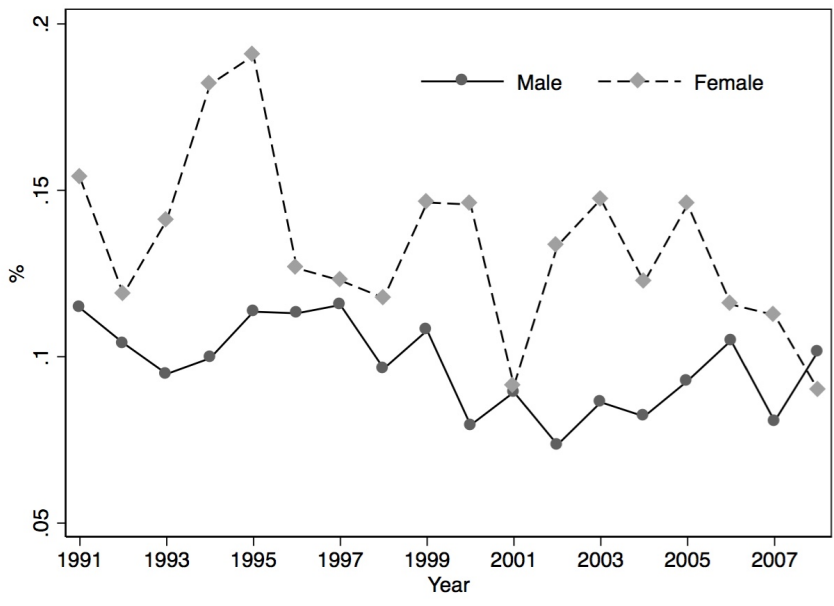

Notes: Rates based on a sample from the British Household Panel Survey (1991-2008) restricted to individuals aged 18 to 65. 
Figure 3: Working Hours for the Entire Sample

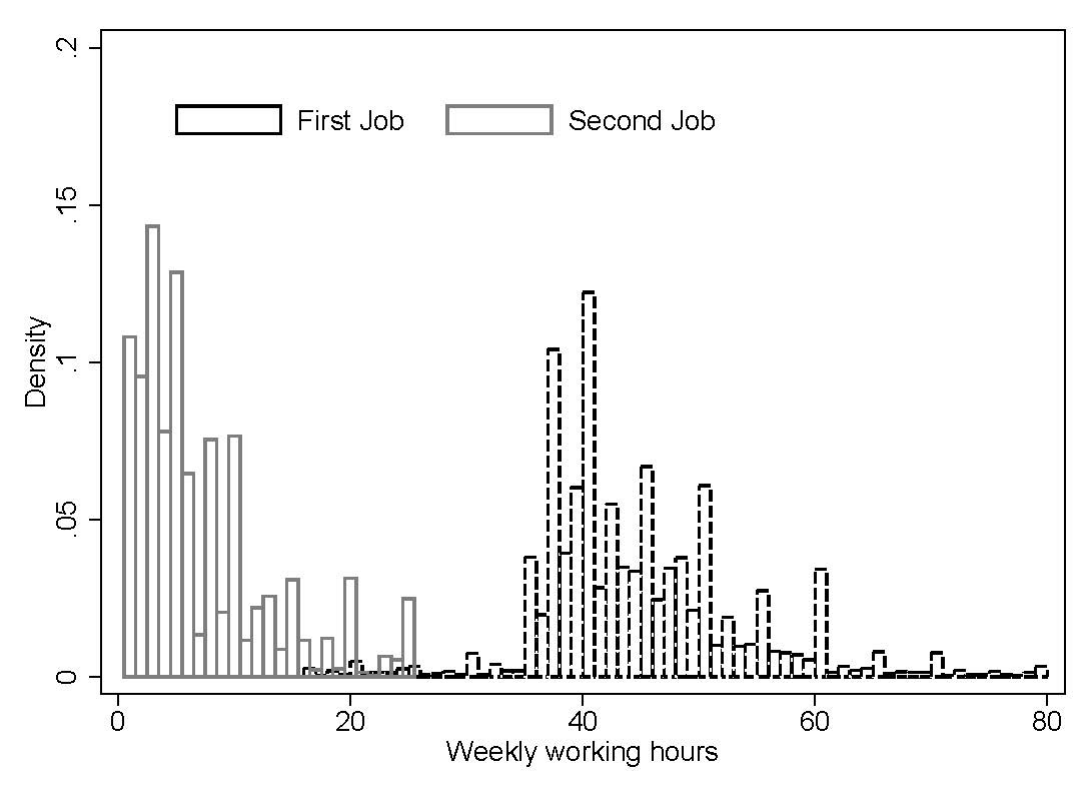

Notes: Rates based on a sample from the British Household Panel Survey (1991-2008) restricted to individuals aged 18 to 65. 


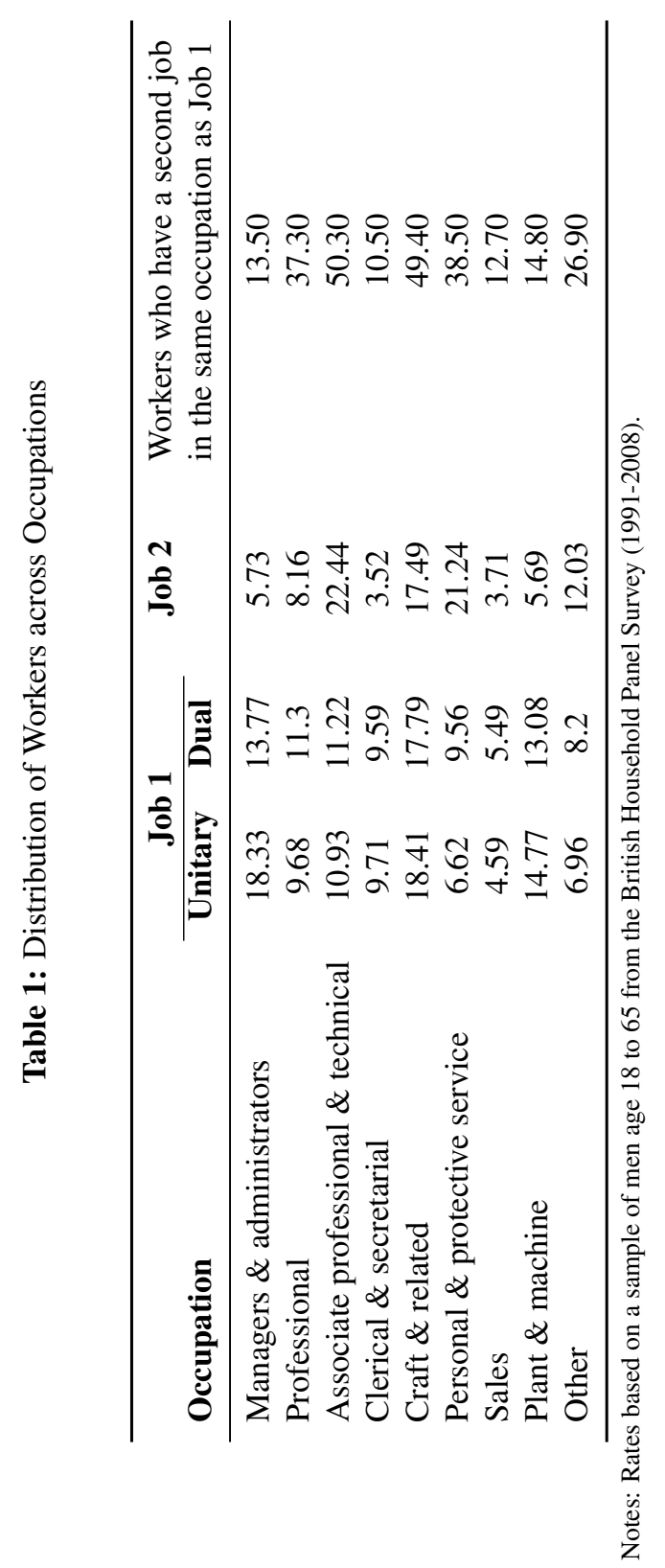




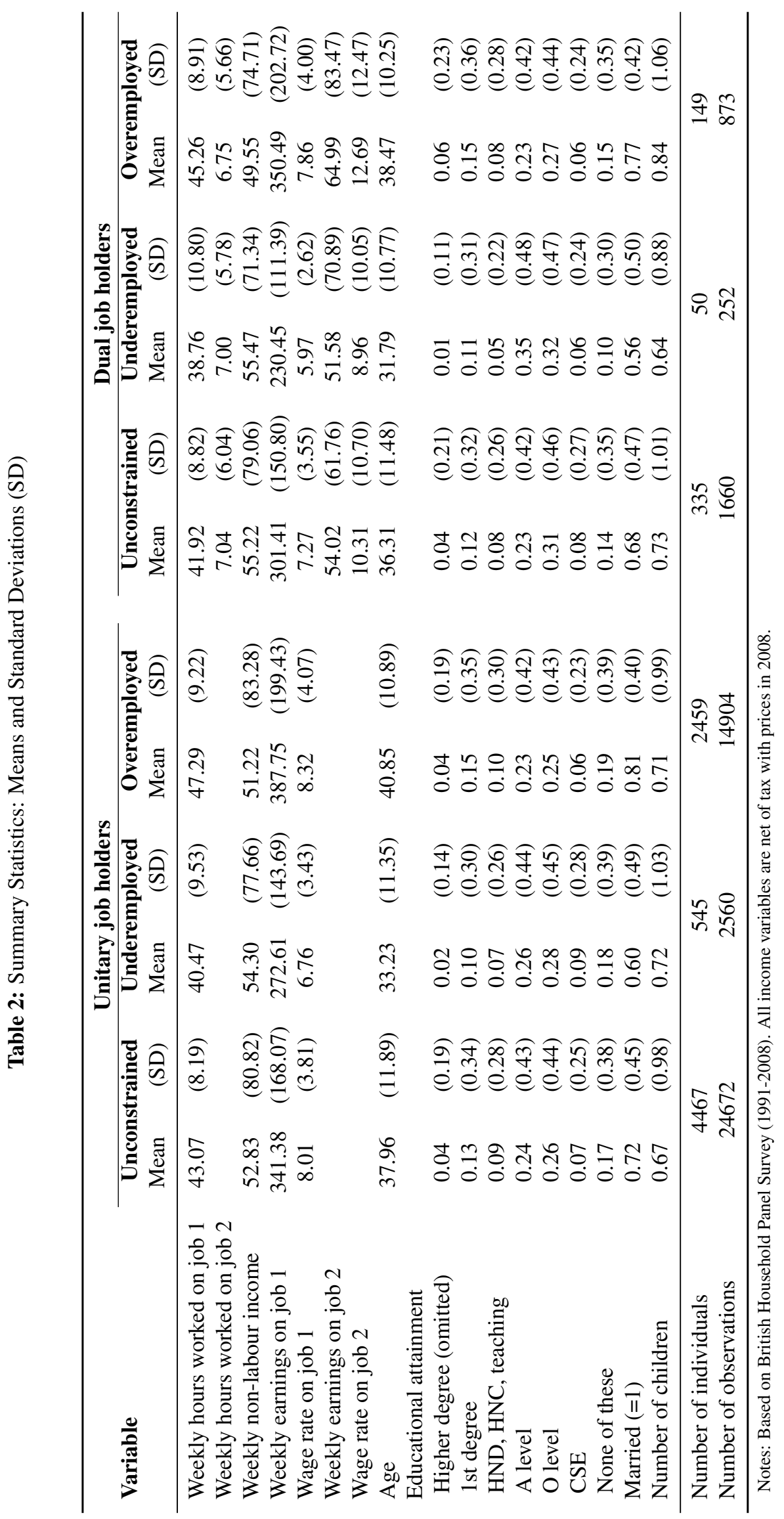




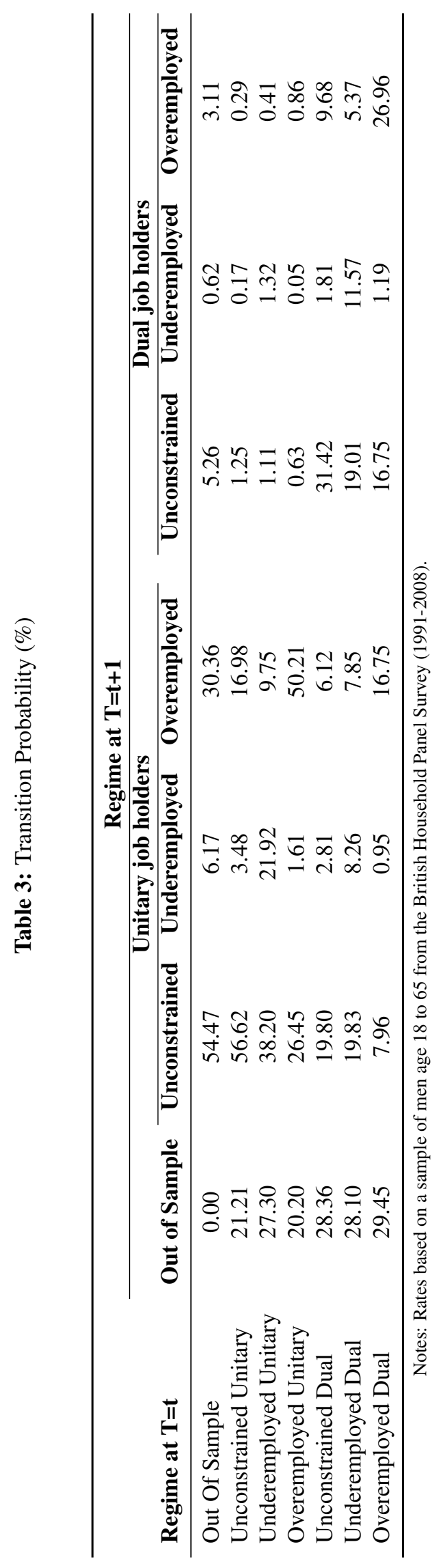




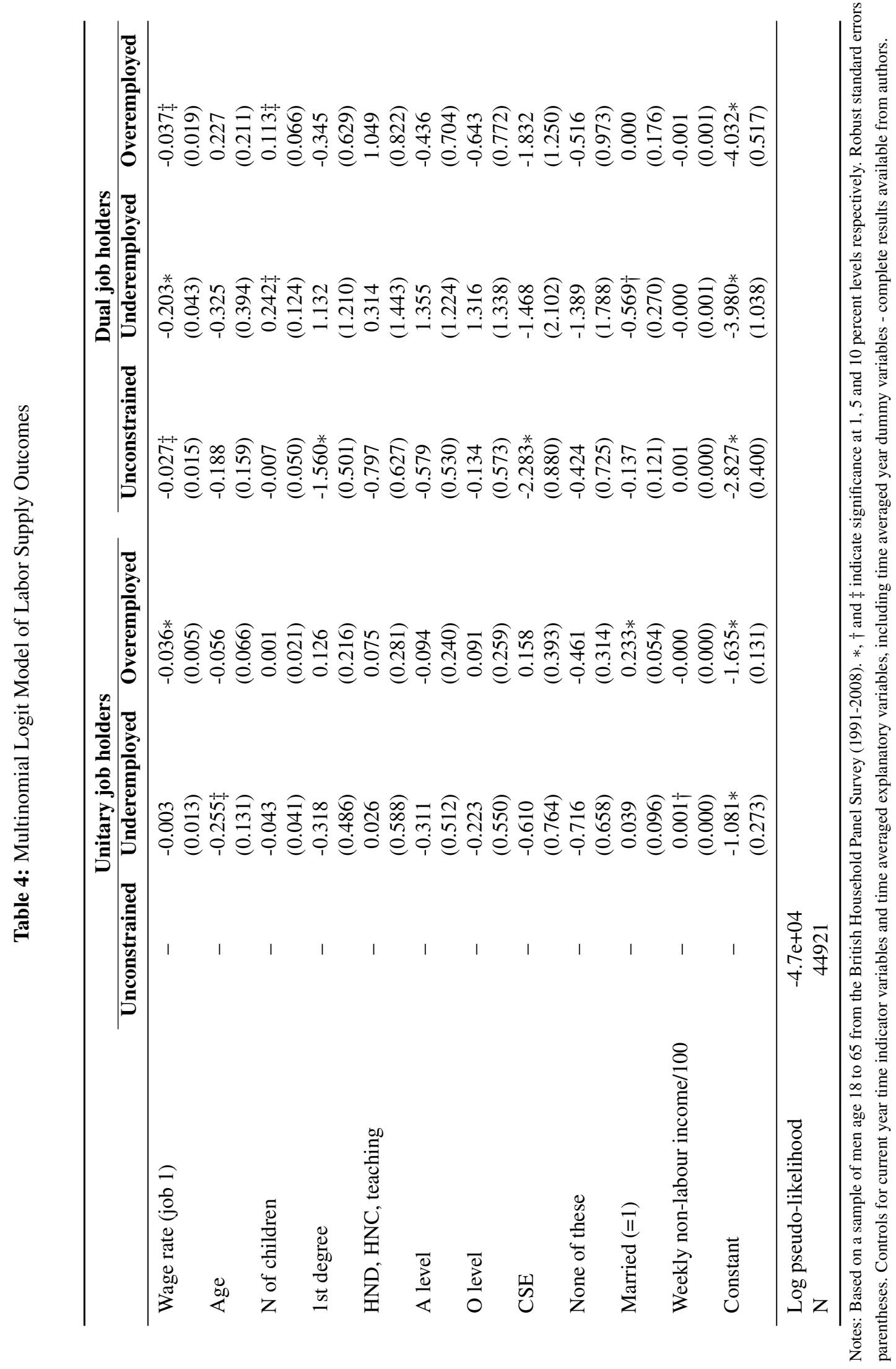


Table 5: Earnings Model Results

\begin{tabular}{|c|c|}
\hline & Boundary Parameters \\
\hline$\widehat{\gamma_{1}}$ & 81 \\
\hline$\widehat{\gamma_{2}}$ & 26 \\
\hline \multirow[t]{2}{*}{$\widehat{\gamma_{3}}$} & 31 \\
\hline & Earnings Model \\
\hline$\widehat{\alpha_{1}}$ & $\begin{array}{c}0.184 * \\
(0.023)\end{array}$ \\
\hline$\widehat{\alpha_{2}}$ & $\begin{array}{c}0.621 * \\
(0.040)\end{array}$ \\
\hline$\widehat{\theta_{12}}$ & $\begin{array}{l}49.487 * \\
(17.507)\end{array}$ \\
\hline$\widehat{\theta_{11}}$ & $\begin{array}{r}-0.865 \\
(12.528)\end{array}$ \\
\hline$\widehat{\theta_{21}}$ & $\begin{array}{l}25.259 \dagger \\
(11.347)\end{array}$ \\
\hline$\widehat{\theta_{23}}$ & $\begin{array}{r}-1.760 \\
(8.630)\end{array}$ \\
\hline$\widehat{\theta_{24}}$ & $\begin{array}{r}-0.445 \\
(18.982)\end{array}$ \\
\hline $\begin{array}{l}\text { Log likelihood } \\
\mathrm{N}\end{array}$ & $\begin{array}{c}-9.3 e+05 \\
44921\end{array}$ \\
\hline
\end{tabular}

Notes: Pooled data from a sample of men age 18 to 65 from the British Household Panel Survey (1991-2008); All income variables are expressed in 2008 prices; Standard errors in parentheses are bootstrap estimates from 200 replications; $*, \dagger$ and $\ddagger$ indicate significance at 1,5 and 10 percent levels respectively; Time averaged explanatory variables are included - complete results available from authors. 


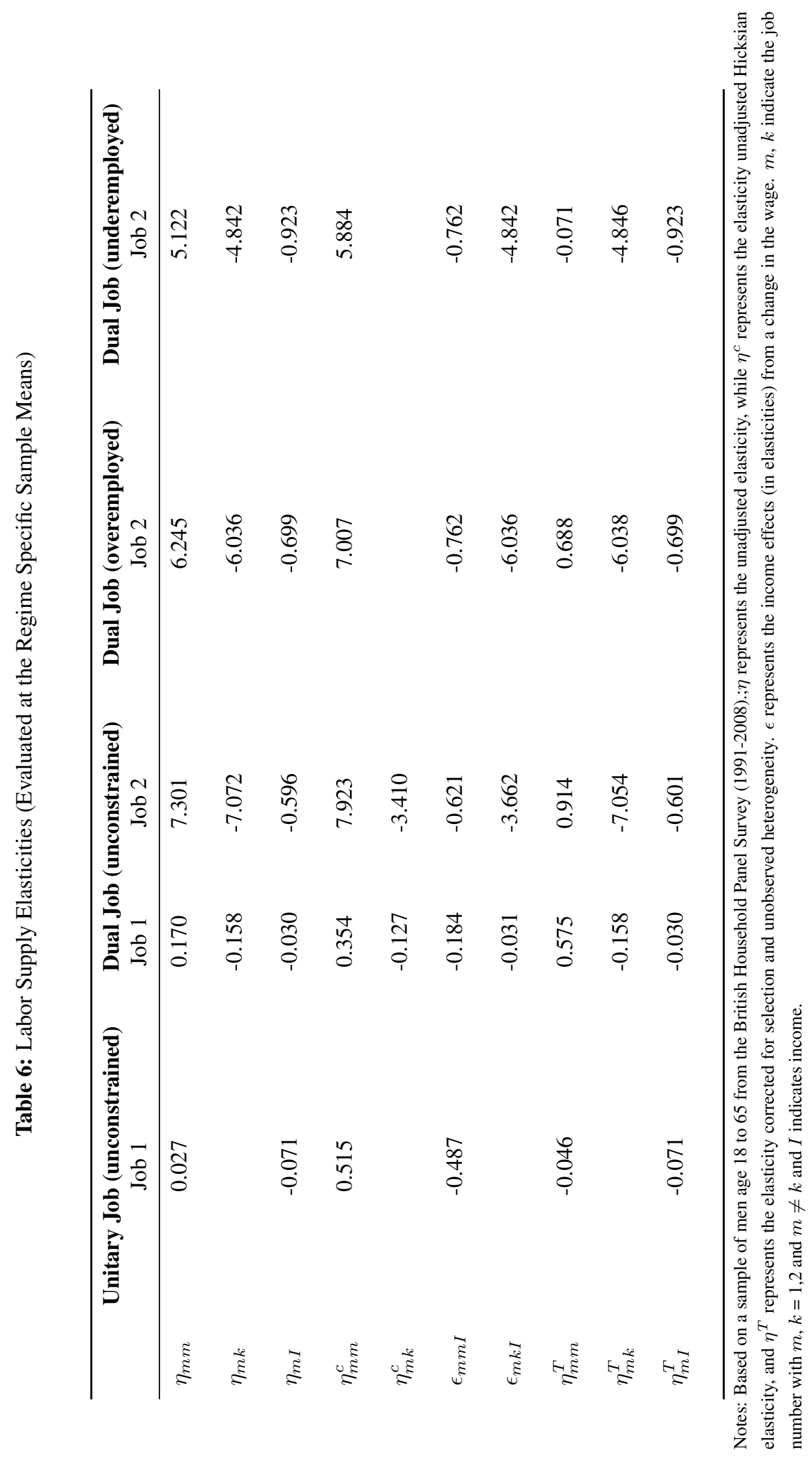




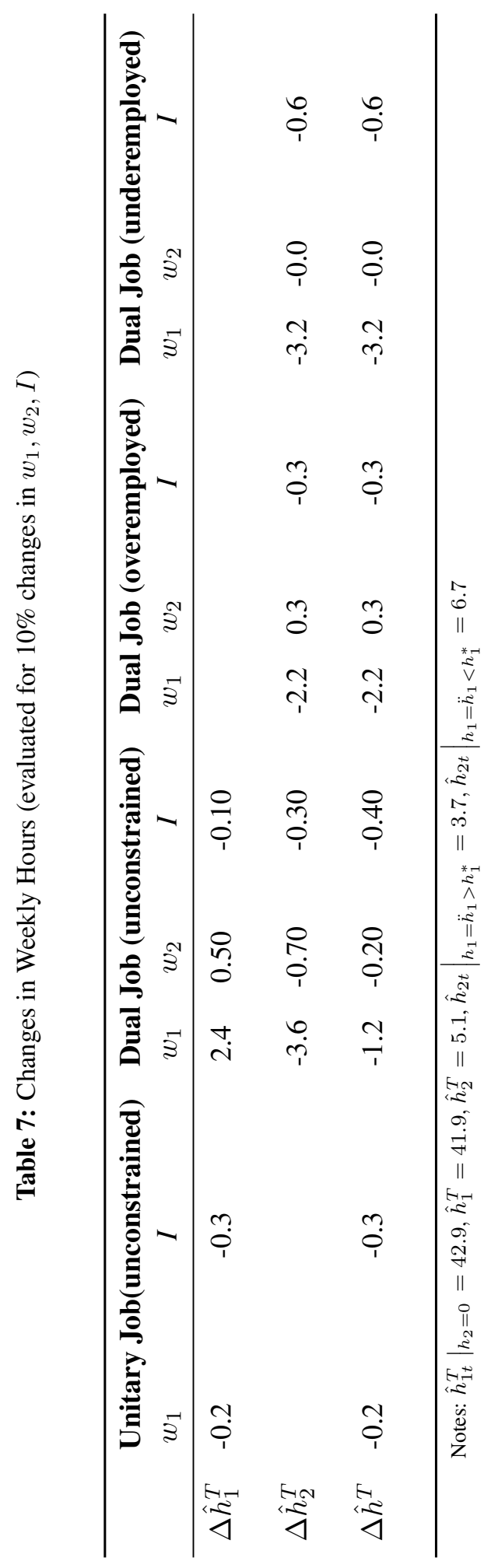

